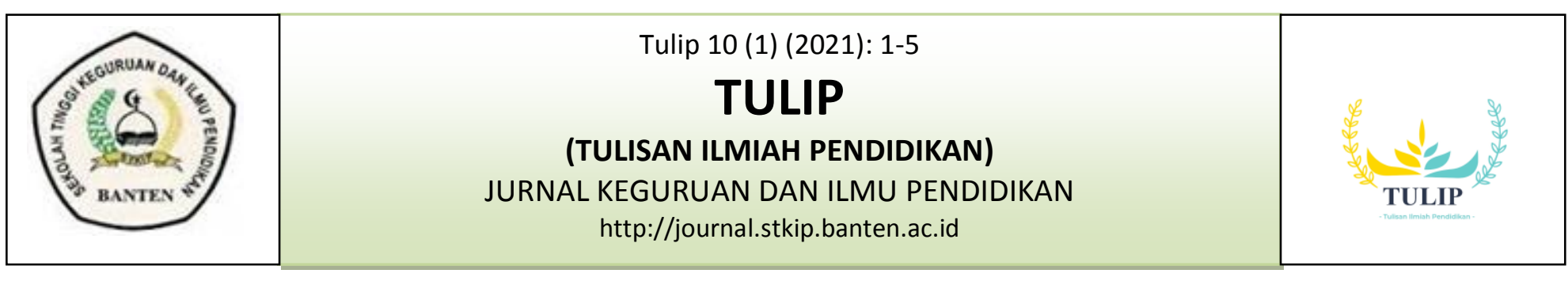

\title{
PENGGUNAAN PANGGUNG BONEKA INTERAKTIF UNTUK MENINGKATKAN KEMAMPUAN INTERAKSI SOSIAL ANAK USIA DINI
}

\author{
Alvan Hazhari ${ }^{1}$ dan Uum Sumiyati ${ }^{2}$ \\ ${ }^{1}$ Sekolah Tinggi Keguruan dan Ilmu Pendidikan Banten \\ ${ }^{2}$ Mahasiswa Pendidikan Guru Pendidikan Anak Usia Dini \\ hazharialvan@gmail.com²dan hjuum720@gmail.com²
}

Penerima: Desember, 2020

Artikel Panggung Boneka Interaktif

Diterima: Januari, 2021

Dipublikasikan: Maret, 2021

\begin{abstract}
The importance of early childhood education has now become an international concern. In the 2000 World Education Forum meeting in Dakkar, Senegal, six agreements were made as a framework for educational action for all (The Dakkar Frame Work for Action Education for All), one of which stated: "Expanding and improving overall care and early childhood education. (PAUD), especially for children who are very vulnerable and less fortunate ". The purpose of this study was to determine the increase in social interaction skills of group early childhood education. This research is a library research (Library Research). Researcher's data collection uses Primary: data reduction, data display, conclusions, Secondary: books, articles, theses, and journals. The results of the research that have been carried out get the percentage results that show an increase in social interaction, seen in the $A_{1}$ data code code $65.6 \%$ increases to $88.1 \%$ so that the increase obtained from $A_{1}$ is $16 \%$. A2 data from $56.63 \%$ to $93.83 \%$ so that the increase obtained from $A_{2}$ is $37.20 \%$. A3 data from $54 \%$ to $70 \%$ so that the increase obtained from $A_{2}$ is $16 \%$. So that the percentage of the average value to improve fine motor skills in early childhood with interactive puppet stage media increased significantly, from $58.74 \%$ before using the media to $83.97 \%$ after using puppet stage media and an increase of $23.06 \%$. So it can be concluded that the model of using interactive puppet stage media can increase social interaction in early childhood.
\end{abstract}

Keywords: Interactive Doll Stage Media, Social Interaction.

\begin{abstract}
Abstrak
Pentingnya pendidikan anak usia dini saat ini telah menjadi perhatian internasional. Dalam pertemuan Forum pendidikan dunia tahun 2000 di Dakkar, Senegal, telah menghasilkan enam kesepakatan sebagai kerangka aksi pendidikan untuk semua (The Dakkar Frame Work for Action Education for All) yang salah satu butirnya menyatakan: "Memperluas dan memperbaiki keseluruhan perawatan dan Pendidikan Anak Usia Dini (PAUD), terutama bagi anak-anak yang sangat rawan dan kurang beruntung". Tujuan penelitian ini adalah untuk mengetahui peningkatan kemampuan interaksi sosial anak usia dini. Peneltian ini adalah penelitian kepustakaan (Library Research), Pengumpulan data peneliti menggunakan Primer : reduksi data, display data, kesimpulan, Sekunder : buku, artikel, skripsi, dan jurnal. Hasil penelitian yang telah dilakukan memperoleh hasil persentase yang menunjukan adanya peningkatan interaksi sosial, terlihat dalam kode kode data $A_{1} 65,6 \%$ meningkat menjadi $88,1 \%$ sehingga peningkatan yang diperoleh dari A1 sebanyak $16 \%$. Data A2 dari 56,63\% menjadi 93,83\% sehingga peningkatan yang diperoleh dari $A_{2}$ sebanyak 37, $20 \%$. Data A3 dari $54 \%$ menjadi 70\% sehingga peningkatan yang diperoleh dari A2 sebanyak 16 $\%$. Sehingga persentasi nilai rata-rata untuk meningkatkan motorik halus pada anak usia dini dengan media panggung boneka interaktif meningkat signifikan yaitu dari $58,74 \%$ sebelum menggunakan media tersebut menjadi $83,97 \%$ sesudah menggunakan media panggung boneka dan peningkatannya sebesar $23,06 \%$. Maka
\end{abstract}

(C) 2021, Tulip, Jurnal Tulisan Ilmiah Pendidikan. STKIPB

ISSN: $2338-6162$ 
hal ini dapat disimpulkan bahwa model Penggunaan media panggung boneka interaktif dapat meningkatkan interaksi sosial pada anak usia dini.

Kata Kunci : Media Panggung Boneka Interaktif, Interaksi Sosial.

\section{PENDAHULUAN}

Pendidikan anak usia dini adalah suatu upaya pembinaan yang ditujukan kepada anak sejak lahir sampai dengan usia 6 tahun yang dilakukan melalui pemberian rangsangan pendidikan untuk membantu pertumbuhan dan perkembangan jasmani dan rohani agar anak memiliki kesiapan dalam memasuki pendidikan lebih lanjut (UU No. 20 Tahun 2003 pasal 1 ayat 14).

Pentingnya pendidikan anak usia dini saat ini telah menjadi perhatian internasional ${ }^{1}$. Dalam pertemuan Forum pendidikan dunia tahun 2000 di Dakkar, Senegal, telah menghasilkan enam kesepakatan sebagai kerangka aksi pendidikan untuk semua (The Dakkar Frame Work for Action Education for All) yang salah satu butirnya menyatakan: "Memperluas dan memperbaiki keseluruhan perawatan dan Pendidikan Anak Usia Dini (PAUD), terutama bagi anak-anak yang sangat rawan dan kurang beruntung".

Secara alamiah, perkembangan anak berbeda-beda, baik intelegensi, bakat, minat, kreativitas, kematangan emosi, kepribadian, kemandirian, jasmani dan sosialnya. Namun penelitian tentang otak menunjukkan bahwa jika anak dirangsang sejak dini, akan ditemukan potensi-potensi yang unggul dalam dirinya. Setiap anak unik, berbeda dan memiliki kemampuan tak terbatas dalam belajar (limitless capacity to learn) yang telah ada dalam dirinya untuk dapat berpikir kreatif dan produktif, mandiri.

\section{METODE}

Penelitian ini dilakukan dengan menggunakan Penelitian Literatur. Dalam melakukan penelitian ilmiah harus dilakukan teknik penyusunan yang sistematis untuk memudahkan langkah-langkah yang akan diambil. Begitu pula yang dilakukan penulis dalam penelitian ini, langkah pertama yaitu dengan melakukan studi literature pada buku-buku yang

\footnotetext{
${ }^{1}$ Kurniasih, Imas. Ragam Pengembangan Moden Pembelajaran (Jakarta : Kata Pena, 2010) hal 5
}

(C) 2021, Tulip, Jurnal Tulisan IImiah Pendidikan. STKIPB ISSN: $2338-6162$ membahas tentang penggunaan media panggung boneka interaktif untuk meningkatkan interaksi sosial anak, jurnal dan penelitian yang didapat dari studi literature ini akan digunakan sebagai acuan untuk membuat penelitian.

Metode penelitan kepustakaan (library research) atau literatur, yaitu serangkaian penelitian yang berkenaan dengan metode pengumpulan data pustaka, atau penelitian yang obyek penelitiannya digali melalui beragam informasi kepustakaan (buku, ensiklopedi, jurnal ilmiah, koran, majalah, dan dokumen).

Data yang digunakan dalam penelitian ini adalah data primer dan sekunder. Data primer yaitu data yang dikumpulkan dan diolah sendiri oleh peneliti langsung dari subjek atau objek penelitian. Data primer yang digunakan dalam penelitian ini adalah reduksi data, display data dan penarikan kesimpulan. Sedangkan Data sekunder merupakan data yang diperoleh bukan dari pengamatan langsung. Akan tetapi data tersebut diperoleh darihasil penelitian yang telah dilakukan oleh peneliti-peneliti terdahulu. Sumber data sekunder yang dimaksud berupa buku dan laporan ilmiah primer atau asli yang terdapat di dalam artikel atau jurnal (tercetak dan / atau non-cetak) berkenaan dengan penggunaan panggung boneka interaktif dan peletakannya dalam aktivitas pembelajaran.

Analisis data merupakan upaya mencari dan menata secara sistematis data yang telah terkumpul untuk meningkatkan pemahaman penelitian tentang kasus yang diteliti dan mengkajinya sebagai temuan bagi orang lain ${ }^{2}$ Analisis data yang digunakan dalam penelitian ini adalah analisis anotasi bibliografi (annotated bibliography).

\section{Reduksi Data}

Dalam kaitan ini peneliti mereduksi data yang telah didapat dari hasil observasi dan wawancara dan dirangkum satu per satu agar memudahkan peneliti dalam memfokuskan data. Data yang tidak

\footnotetext{
${ }^{2}$ Noeng Mohadjir dalam YuniIrawati.2013. Metode Pendidikan Karakter Islami Terhadap Anak Menurut Abdullah Nasih Ulwan dalam Buku Pendidikan Anak dalam Islam dan Relevansinya dengan Tujuan Pendidikan Nasional.Skripsi tidak diterbitkan.UIN Sunan Kalijaga.h.28.
} 
terkait dengan permasalahahan tidak disajikan dalam bentuk laporan.

2. Display Data

Setelah data direduksi maka langkah selanjutnya adalah menyajikan data (Display Data). Data yang berupa tulisan tersebut disusun kembali secara baik dan akurat untuk dapat memperoleh kesimpulan yang valid sehingga lebih memudahkan peneliti dalam memahami. Penyajian data dalam penelitian kualitatif berbentuk uraian yang singkat dan jelas.

3. Menarik Kesimpulan

Penarikan kesimpulan merupakan bagian dari aktivitas data. Aktivitas ini dimaksudkan untuk memberikan makna terhadap hasil analisis, menjelaskan pola urutan dan mencari hubungan diantara dimensi-dimensi yang diuraikan. Disamping itu, kendati data telah disajikan bukan berarti proses analisis data sudah final.

\section{HASIL DAN PEMBAHASAN}

\section{Hasil Penelitian}

Hasil penelitian dari tabel diatas adalah Kode data $\mathrm{A}_{1}$ skor pretes menunjukan data dari $65,6 \%$ menjadi $88,1 \%$ sehingga peningkatannya $22,5 \%$. Kode data $A_{2}$ menunjukan dari 56,63 menjadi 93,83 dengan peningkatan mencapai $37,20$.

Kode data $\mathrm{A} 3$ dari $54 \%$ menjadi $70 \%$ dengan peningkatan mencapai $16 \%$. Rata-rata hasil pencapaian dari ketiga judul yang dianalisis sebelum menggunakam model pembelajaran media lipat kertas yaitu $33,02 \%$ dan sesudah menggunakan media lipat kertas meningkat menjadi $64,43 \%$ dengan rata-rata peningkatan $31,41 \%$.

\section{Pembahasan}

Dari pembahasan diatas tentang Pembelajaran dengan menggunakan media panggung boneka interaktif sangat berpengaruh terhadap peningkatan interaksi sosial pada anak usia dini. Boneka menjadi sesuatu yang hidup dalam imajinasi anak dan menjadi peraga yang dianggap mendekati naturalis bercerita. Melalui boneka, anak tahu tokoh mana yang sedang berbicara, apa isi pembicaraannya, dan bagaimana perilakunya.

Cerita anak merupakan salah satu bentuk sastra anak, oleh karena itu cerita untuk anak adalah cerita yang menempatkan mata anak-anak sebagai pengamat utama dan masa anak-anak

(C) 2021, Tulip, Jurnal Tulisan Ilmiah Pendidikan. STKIPB ISSN: $2338-6162$ sebagai fokusnya. Jadi dapat ditegaskan perasaan dan pengalaman anak-anak masa kini, yang dapat dilihat dan dipahami melalui mata anak. ${ }^{3}$

Merencanakan pembelajaran harus dipersiapkan dengan matang. Guru harus memiliki pengetahuan situasi umum yang akan dihadapi, misalnya saja, tempat, situasi, dan lain-lain. Persiapan terhadap murid-murid dalam mempersiapkan pembelajaran guru juga harus mempersiapkan murid-murid, dan guru harus memiliki gambaran murid-muridnya. ${ }^{4}$

Cara yang paling tepat untuk mengembangkan kemampuan anak PAUD adalah melalui pembelajaran yang menekankan pada kegiatan bermain karena dunia anak adalah dunia bermain. Permainan yang digunakan di PAUD merupakan permainan yang didesain sedemikian rupa sehingga merangsang kreativitas anak dan menyenangkan. ${ }^{5}$

Berdasarkan tabel diatas menyebutkan bahwa adanya peningkatan interaksi sosial pada anak usia dini dengan menggunakan media panggung boneka interaktif. Dilihat dari data $\mathrm{A}_{1}$ $65,6 \%$ meningkat menjadi $88,1 \%$ sehingga peningkatan yang diperoleh dari A1 sebanyak 16 $\%$.

Data $A_{2}$ dari $56,63 \%$ menjadi $93,83 \%$ sehingga peningkatan yang diperoleh dari $\mathrm{A}_{2}$ sebanyak 37, $20 \%$. Data $\mathrm{A}_{3}$ dari $54 \%$ menjadi $70 \%$ sehingga peningkatan yang diperoleh dari A2 sebanyak $16 \%$.

Sehingga persentasi nilai rata-rata untuk meningkatkan motorik halus pada anak usia dini dengan media panggung boneka interaktif meningkat signifikan yaitu dari $58,74 \%$ sebelum menggunakan media tersebut menjadi $83,97 \%$ sesudah menggunakan media panggung boneka. Maka hal ini dapat disimpulkan bahwa model Penggunaan media panggung boneka interaktif dapat meningkatkan interaksi sosial pada anak usia dini.

\section{PENUTUP}

3 Depdiknas, Pedoman Pembuatan Cerita Anak untuk Taman Kanak-Kanak, (Jakarta: Departemen Pendidikan Nasional Direktorat Jendral Managemen Pendidikan Dasar dan Menengah Direktorat Pembinaan Taman Kanak-Kanak dan Sekolah Dasar, 2006). HIm 3

\footnotetext{
${ }^{4}$ Mursid. (2018). Belajar dan Pembelajaran PAUD. Bandung : Remaja Rosdakarya. Hal 64

${ }^{5}$ Mursid. (2018). Belajar dan Pembelajaran PAUD.

Bandung : Remaja Rosdakarya. Hal 61
} 


\section{Simpulan}

Berdasarkan hasil penelitian diatas tentang pembelajaran panggung boneka interaktif untuk meningkatkan kemampuan interaksi sosial anak usia dini. Hasil penelitiannya adalah bahwa setiap penelitian yang telah dilakukan dan telah memperoleh hasil presentase yang menunjukan adanya peningkatan kemampuan interaksi sosial anak, dapat disimpulkan bahwa:

Terdapat peningkatan kemampuan interaksi sosial anak usia dini dengan menggunakan panggung boneka interaktif, dengan peningkatan 23,06 \%, karena dengan panggung boneka interaktif anak dapat Menghidupkan latar cerita, Memperjelas isi cerita, Mengembangkan daya imajinasi siswa yang dapat dilihat secara langsung dan Memberikan pengalaman secara langsung

\section{Saran}

Berdasarkan simpulan diatas, maka peneliti mengajukan beberapa saran sebagai berikut:

1. Bagi guru, disarankan agar menggunakan media pembelajaran setiap pembelajaran yang akan disampaikan, khususnya dalam mengajarkan anak dalam interaksi sosial dengan menggunakan media panggung boneka interaktif, agar anak lebih tertarik dalam mengikuti pembelajaran.

2. Bagi Siswa, dengan adanya penelitian ini seyogyanya dapat berguna untuk dijadikan pemahaman bagi siswa dalam belajar diperlukan kesungguhan dan niat yang baik agar mendapatkan ilmu yang bermanfaat.

3. Bagi pihak sekolah, disarankan lebih memperhatikan kemampuan membaca didalam kelas, caranya dengan menyediakan media atau alat peraga. Karena dengan media anak lebih cepat memahami maksud dari penyampaian guru dan anak usia dini pada umumnya cara berfikir anak di masa pra sekolah masih bersifat yang kongrit benda-benda yang langsung dilihatnya.

4. Bagi Peneliti selanjutnya yang ingin mengadakan penelitian lebih lanjut terhadap cara meningkatkan kemampuan interaksi sosial dengan menggunakan media panggung boneka interaktif disarankan untuk lebih dalam lagi meneliti materi ini, karena masih banyak hal menarik yang dapat diperoleh dengan menggunakan media pembelajaran yang lebih menarik lagi sehingga memperoleh hasil yang lebih maksimal nantinya.

\section{DAFTAR PUSTAKA}

Adrianindita, Syahisnu. (2015). Upaya Meningkatkan Keterampilan SosialEmosional Anak Usia 2-3 Tahun Melalui Metode Bercerita di KB Siti Sulaechah o4 Semarang. Semarang: Jurnal Jurusan PG-PAUD Universitas Negeri Semarang

Arikunto, Suharsimi. (2010). Prosedur Penelitian Suatu Pendekatan Praktik.Jakarta: Rineka Cipta

Arsyad, Azhar. (2014). Media Pembelajaran. Jakarta: Rajawali Pers

Arsyad . (2017). Pengembangan Media Pembelajaran. Yogyakarta: Pedagogia

Azwar, Saifuddin. (2011). ReliabilitasdanValiditas. Yogyakarta: Pustaka Pelajar

Daryanto, (2010). Media Pembelajaran Peranannya Sangat Penting dalam Mencapai Tujuan Pembelajaran, (Yogyakarta: Gava Media). HIm 29

Bangun Datar Pada Pembelajaran Matematika Menggunakan Media Kertas Lipat, (Skripsi FKIP UNPAS), hlm. 57

Departemen Pendidikan Nasional Direktorat Jenderal Pendidikan Tinggi Direktorat Pembinaan Pendidikan Tenaga Kependidikan dan Ketenagaan Perguruan Tinggi

Depdiknas, (2006). Pedoman Pembuatan Cerita Anak untuk Taman Kanak-Kanak, (Jakarta: Departemen Pendidikan Nasional Direktorat Jendral Managemen Pendidikan Dasar dan Menengah Direktorat Pembinaan Taman Kanak-Kanak dan Sekolah Dasar). Hlm 3

Diantama.Suarifqi. (2018). Metode Penelitian Pendidikan. Bandung:Pustaka Rahmat. Hal 27

Eliyawati, Cucu. (2005). Pemilihan dan Pengembangan Sumber Belajar Untuk Anak Usia Dini. Jakarta: Departemen Pendidikan Nasional Direktorat Jenderal Pendidikan Tinggi Direktorat Pembinaan Pendidikan Tenaga Kependidikan dan Ketenagaan Perguruan Tinggi. Hal 104 
Gerungan.(2010).,Interaksi

Sosia.

Jakarta:Kencana. Hal 62

Kurniasih, Imas. (2010). Ragam Pengembangan Moden Pembelajaran (Jakarta : Kata Pena) hal 5

Latif, Mukhtar, dkk. (2013). Orientasi Baru Pendidikan Anak Usia Dini Teori dan Aplikasi. Jakarta: Prenada Media Group. Hal 151

Latif, Mukhtar, dkk. (2013). Orientasi Baru Pendidikan Anak Usia Dini Teori dan Aplikasi. Jakarta: Prenada Media Group. Hal 152

Mardianingsih, Ratih. (2016). Kemampuan Interaksi Sosial Anak Usia Dini Ditinjau dari Penggunaan Media Puisi Naratif di Kelompok A TKIT Robbani Kendal. Semarang: Skripsi Jurusan PG-PAUD UNNES

Mayar, Farida. (2013). Perkembangan Sosial Anak Usia Dini Sebagai Bibi tuntuk Masa Depan Bangsa. Padang: Jurnal Al-Ta'lim

Mursid. (2018). Belajar dan Pembelajaran PAUD. Bandung : Remaja Rosdakarya. Hal 64

Mursid. (2018). Belajar dan Pembelajaran PAUD. Bandung : Remaja Rosdakarya. Hal 61

Mursid. (2018). Belajar dan Pembelajaran PAUD. Bandung : Remaja Rosdakarya. Hal 48.

Nana Syaodih kumadinata. (2017). Metode Penelitian Pendidikan. Remaja sodya karya hal 42

Noeng Mohadjir dalam Yuni Irawati.(2013). Metode Pendidikan Karakter Islami Terhadap Anak Menurut Abdullah Nasih Ulwan dalam Buku Pendidikan Anak dalam Islam dan Relevansinya dengan Tujuan Pendidikan Nasional.Skripsi tidak diterbitkan.UIN Sunan Kalijaga.h.28.

Nurbiana Dhieni, (2006). Metode Pengembangan Bahasa, (Jakarta: Universitas Terbuka). HIm 54

Rindy Jihan Permatasari, (2013). https://lib.unnes.ac.id/17330/1/1301408063.pdf.

(C) 2021, Tulip, Jurnal Tulisan IImiah Pendidikan. STKIPB

ISSN: $2338-6162$
Santosa, Slamet. (2014). Teori-Teori Psikologi Sosial.Bandung:Refika Aditama. Hal11

Soekanto, Soerjono. (2012). Sosiologi Suatu Pengantar. Jakarta: Rajawali Pers

Sugiyono. (2012). Pendidikan Pendekatan Interaksi Sosial. Bandung: Alfabeta

Sugiyono. (2012). Metode Penelitian Pendidikan Pendekatan Kuantitatif, Kualitatif, dan R\&D. Bandung: Alfabeta

Sujiono, Bambang \& Yuliani N.S. (2005). Mencerdaskan Perilaku Anak Usia Dini Panduan Bagi Orang Tua dalam Membina

Sukiman. (2012). Pengembangan Media Pembelajaran. Yogyakarta: Pedagogia

Sukmadinata, Nana Syaodih. (2009). Metode Penelitian Pendidikan. Bandung: PT Remaja Rosdakarya

Susanto, Ahmad. (2011). Perkembangan Anak Usia Dini Pengantar dalamBerbagai Aspeknya. Jakarta: Kencana

The UCSC University Library. (2020). Write a Literature Review (http://guides.library.ucsc.edu/write-aliterature-review diakses tanggal 15 Mei 2020).

Walgito, Bimo. (2010). Psikologi Sosial (Suatu Pengantar). (Yogyakarta: Penerbit .Andi) hal 65 